\title{
PAR2 absence completely rescues inflammation and ichthyosis caused by altered CAP1/Prss8 expression in mouse skin
}

\author{
Simona Frateschi', Eric Camerer ${ }^{2,3}$, Giovanna Crisante1, Sarah Rieser ${ }^{1}$, Mathieu Membrez ${ }^{1, i}$, Roch-Philippe \\ Charles ${ }^{1, i}$, Friedrich Beermann ${ }^{4}$, Jean-Christophe Stehle ${ }^{5}$, Bernadette Breiden ${ }^{6}$, Konrad Sandhoff ${ }^{6}$, \\ Samuel Rotman ${ }^{5}$, Marek Haftek ${ }^{7}$, Anne Wilson ${ }^{8}$, Stephan Ryser ${ }^{9}$, Martin Steinhoff ${ }^{10}$, Shaun R. Coughlin ${ }^{2}$ \\ $\&$ Edith Hummler
}

Altered serine protease activity is associated with skin disorders in humans and in mice. The serine protease channel-activating protease-1 (CAP1; also termed protease serine S1 family member 8 (Prss8)) is important for epidermal homeostasis and is thus indispensable for postnatal survival in mice, but its roles and effectors in skin pathology are poorly defined. In this paper, we report that transgenic expression in mouse skin of either CAP1/Prss8 (K14-CAP1/Prss8) or protease-activated receptor-2 (PAR2; Grh/3PA22+ $)$, one candidate downstream target, causes epidermal hyperplasia, ichthyosis and itching. K14-CAP1/Prss8 ectopic expression impairs epidermal barrier function and causes skin inflammation characterized by an increase in thymic stromal lymphopoietin levels and immune cell infiltrations. Strikingly, both gross and functional K14-CAP1/Prss8-induced phenotypes are completely negated when superimposed on a PAR2-null background, establishing PAR2 as a pivotal mediator of pathogenesis. Our data provide genetic evidence for PAR2 as a downstream effector of CAP1/Prss8 in a signalling cascade that may provide novel therapeutic targets for ichthyoses, pruritus and inflammatory skin diseases.

\footnotetext{
'Department of Pharmacology and Toxicology, University of Lausanne, Lausanne 1005, Switzerland. ${ }^{2}$ Cardiovascular Research Institute, University of California, San Francisco, California 94158, USA. ${ }^{3}$ Equipe Avenir, Inserm Unit 970, Paris Cardiovascular Research Center, Paris 75006, France. ${ }^{4}$ Swiss Institute for Experimental Cancer Research (ISREC), School of Life Sciences, Ecole Polytechnique Fédérale de Lausanne (EPFL), Lausanne 1015, Switzerland. ${ }^{5}$ Pathology Department, University of Lausanne, Lausanne 1011, Switzerland. ${ }^{6}$ LIMES, Membrane Biology \& Lipid Biochemistry Unit c/o Kekulé-Institut für Organische Chemie und Biochemie der Universität, University of Bonn, Bonn 53121, Germany. ${ }^{7}$ University of Lyon, EA4169: Normal and Pathological Functions of the Skin Barrier, Lyon F-69437, France. ${ }^{8}$ Ludwig Institute for Cancer Research, University of Lausanne, Epalinges 1066, Switzerland. ${ }^{9}$ Laboratory of Cutaneous Biology, CHUV, University of Lausanne, Lausanne 1011, Switzerland. ${ }^{10}$ Department of Dermatology, University of California, San Francisco, California 94115, USA. †Present addresses: Nestlé Research Center, Lausanne 1000, Switzerland (M.M); Cancer Research Institute, University of California, San Francisco, California 94158, USA (R.-P.C.). Correspondence and requests for materials should be addressed to E.H. (email: Edith.Hummler@unil.ch).
} 
$\mathrm{H}$ uman skin disorders such as atopic dermatitis, psoriasis and ichthyoses range in severity from mild to life threatening, and share characteristics of inflammation, defects in epidermal barrier function, skin desquamation and pruritus in affected patients (reviewed in refs 1 and 2). Our understanding of their molecular and genetic origins is improving ${ }^{3-5}$, with serine proteases emerging among possible disease-causing culprits. Genetargeting experiments in mice revealed a critical role for membranebound serine proteases, particularly those of the $\mathrm{S} 1$ or trypsin-like family $^{6}$ in postnatal epidermal barrier function ${ }^{7-9}$. It also emerged that inadequate regulation of serine protease activity in the skin of both mice $\mathrm{e}^{7,8,10}$ and humans ${ }^{4}$ could disrupt skin homeostasis. However, which serine proteases need to be tightly regulated to prevent disease and how they mediate skin pathology when deregulated are still incompletely defined.

Channel-activating protease-1 (CAP1; also termed protease serine S1 family member-8 (Prss8)), the mouse homologue of human prostasin, is a glycosylphosphatidylinositol-anchored serine protease $^{11}$. CAP1/Prss8 is expressed at high levels in the prostate gland ${ }^{12}$, and is also found in a variety of other organs such as skin, colon, lung and kidney ${ }^{13}$. We have previously shown that CAP1/ Prss8 is predominantly expressed in granular and spinous layers of the epidermis where it is crucial for epidermal barrier function and thereby indispensable for postnatal survival ${ }^{8}$. Membrane-bound serine proteases exhibit pleiotropic functions not only by cleaving growth factors, zymogen proteases and extracellular matrix proteins ${ }^{14}$ but also by inducing cell signalling through members of the proteinase-activated receptor (PAR) family of G-protein-coupled receptors ${ }^{15}$. It was recently demonstrated that CAP1/Prss8 can function upstream in a proteolytic cascade that culminates in PAR2 activation $^{16}$; yet, genetic evidence that CAP1/Prss8 can evoke PAR2 signalling in vivo is lacking. PAR2 is widely expressed in skin, including keratinocytes, endothelial cells and sensory nerves ${ }^{17-20,}$ in which it has already been implicated in the regulation of keratinocyte proliferation and differentiation ${ }^{21}$, maintenance of the epidermal barrier ${ }^{22}$, inflammation ${ }^{17,18}$ and pruritus ${ }^{20,23}$. Both CAP1/Prss8 and PAR2 are expressed in the suprabasal granular layers of the epidermis ${ }^{8,17,24}$, supporting a possible interaction between the two.

In this study, to directly address the potential contribution of deregulated CAP1/Prss8 and PAR2 expression to skin pathology, we manipulated epidermal CAP1/Prss 8 and PAR2 expression in transgenic mouse lines (K14-CAP1/Prss8, Grhl3 ${ }^{\text {PAR2/+ }}$ ). The two models yielded modestly increased as well as ectopic expression of CAP1/ Prss8 or PAR2, and exhibited similar phenotypes characterized by scaly skin, hyperplastic epidermis and scratching behaviour. Having established the ability of protease and signalling receptor to independently cause skin pathology, we addressed whether they also cooperated to drive pathogenesis as might be suggested by signalling studies ${ }^{16}$. We indeed observed that the K14-CAP1/Prss 8 transgene completely lost its capacity to induce skin pathology in the absence of PAR2, placing PAR2 as a pivotal mediator downstream of CAP1/Prss 8 in this model. We thus demonstrate that altered CAP1/Prss8 expression triggers PAR2-dependent inflammation, ichthyosis and itching, supporting the requirement for tight control of protease activity in skin homeostasis, and implicating PAR2 as a potential mediator of pathologies linked to loss of serine protease regulation in skin.

\section{Results}

Generation and characterization of K14-CAP1/Prss8 mice. To study the biological consequence of deregulated CAP1/Prss8 expression in skin, we generated transgenic mice expressing the full-length mouse CAP1/Prss 8 coding sequence ${ }^{13}$ under the control of the human keratin-14 promoter $^{25}$ (Fig. 1a). This promoter targets gene expression to keratinocytes of the basal layer of the epidermis and the outer root sheath of hair follicles ${ }^{25}$. Pronuclear injections of the K14-CAP1/Prss 8 transgene construct yielded five founders, two of which were fertile and transmitted the transgene to produce two independent stable transgenic lines (termed lines 1 and 2; Fig. 1b,c). The transgene was transmitted according to Mendelian inheritance in both lines (line 1: $54 \% \operatorname{tg}, n=95$; line $2: 54 \% \operatorname{tg}, n=72$ ), suggesting that the level of CAP1/Prss8 expression obtained did not interfere with embryonic development. For line 1, only male mice (all of them) were transgenic, indicating integration of the transgene into the $\mathrm{Y}$ chromosome. Both transgenic lines expressed the transgene in skin as determined by immunohistochemistry (Fig. 1d; Supplementary Fig. S1a). Analysis of total (transgene-driven plus endogenous) expression of CAP1/Prss8 demonstrated a 1.1- and 4.7-fold increase in transcript levels and a 1.1- and 2.9-fold increase in protein levels in lines 1 and 2, respectively (Fig. 1e,f), indicating higher CAP1/ Prss8 expression levels in line 2.

Epidermal defects and death in K14-CAP1/Prss8 mice. K14$C A P 1 / \operatorname{Prss} 8$ transgenic mice were easily discernible from their control littermates just a few days after birth by their scaly skin (ichthyosis), which progressed with age and was evident most prominently in the ventral-abdominal region and the tail (line 2, Fig. 2a, line 1; Supplementary Fig. S1b). Both transgenic lines manifested ichthyosis with $100 \%$ penetrance, as well as abnormal hair growth (hypotrichosis) relative to littermate controls (Fig. 2b). No histopathological abnormalities were observed in other organs, such as thymus, tongue, oesophagus, heart, liver, lung and spleen (Supplementary Fig. S2). Histological analysis revealed epidermal hyperplasia (acanthosis) in transgenic mice from as early as 2 days of age (Fig. 2c; Supplementary Fig. S1c) associated with enhanced proliferation of keratinocytes, as evidenced by a threefold increase in the number of Ki67-positive cells in the stratum basale (Fig. 2d), without an accompanying change in the number of apoptotic cells in the epidermis (Fig. 2e). In addition to epidermal hyperplasia, the dermis of K14-CAP1/Prss 8 transgenic mice was more cellular with a notable increase in the number of haematoxylin-stained nuclei (Fig. 2c).

Despite differences in CAP1/Prss8 expression levels, mice from both transgenic lines also manifested a significant reduction in body weight (Fig. 2f; Supplementary Fig. S1d) accompanied by an up to twofold increase in transepidermal water loss (TEWL) evident in 2-week-old animals (Fig. 2g; Supplementary Fig. S1e) and maintained in adults (TEWL: $3.31 \mathrm{~g} \mathrm{~m}^{-2} \mathrm{~h}^{-1}$ in wild type (wt) versus $6.90 \mathrm{~g} \mathrm{~m}^{-2} \mathrm{~h}^{-1}$ in tg, $P<0.05, n=6$ and 7 , respectively, in line 1 . $2.87 \mathrm{~g} \mathrm{~m}^{-2} \mathrm{~h}^{-1}$ in wt versus $6.02 \mathrm{~g} \mathrm{~m}^{-2} \mathrm{~h}^{-1}$ in $\mathrm{tg}, P<0.05, n=6$ and 4 , respectively, in line 2; Body weight: $37.49 \mathrm{~g}$ in wt versus $32.62 \mathrm{~g}$ in $\operatorname{tg}, n=6$ and 7 , respectively, in line 1 and $37.64 \mathrm{~g}$ in wt versus $26.06 \mathrm{~g}$ in $\operatorname{tg}, P<0.001, n=6$ and 4 , respectively, in line 2 ) indicative of a defect in the skin barrier function. Many transgenic mice from line 2 died within the first 2 weeks ( 55 versus $10 \%$ in line 1 , Fig. 2h; Supplementary Fig. S1f), but survival was not further impaired thereafter. Although we did not address it directly, we speculate that death of these animals may be a consequence of severe dehydration.

Altered lipid and protein content in K14-CAP1/Prss8 mice. To explore the basis for skin barrier defects observed in K14-CAP1/ Prss 8 transgenic mice, we first looked for alterations in expression of keratinocyte differentiation markers by immunohistochemistry and western blot. Expression of keratin-1, loricrin, filaggrin and involucrin appeared to be more widespread within the epidermis of K14-CAP1/Prss 8 mice, but there was no obvious change in distribution within the differentiated layers (Fig. 3a; Supplementary Fig. S1g), and expression levels were normal with the exception of filaggrin. Levels of all proteolytically cleaved intermediates of filaggrin were increased (Fig. 3b,c; Supplementary Fig. S1h,i). Moreover, the differentiation marker keratin-14, normally expressed 
a

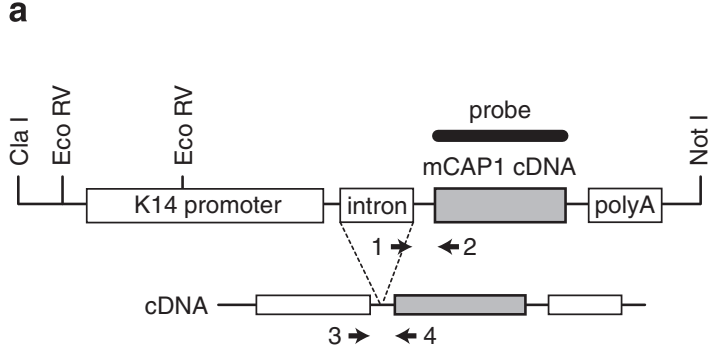

b

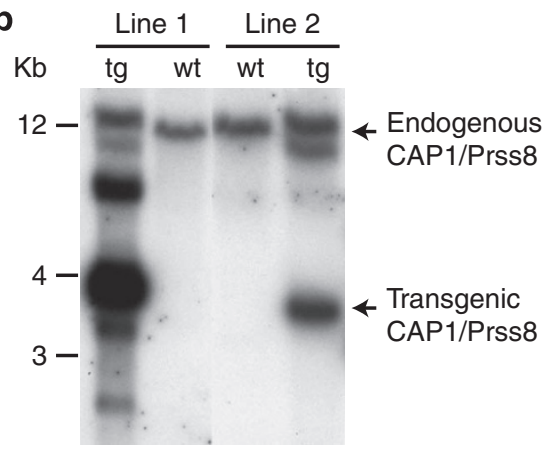

C
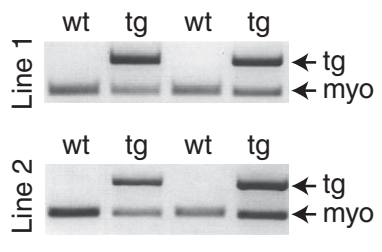

d

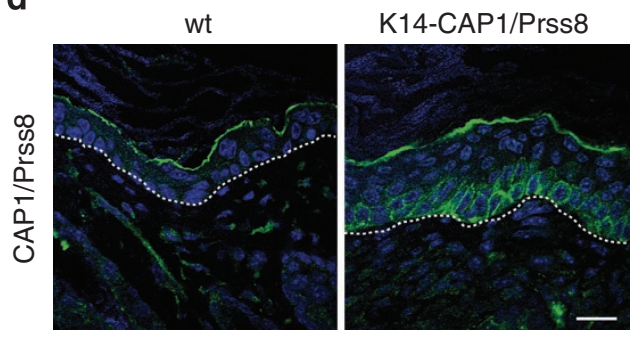

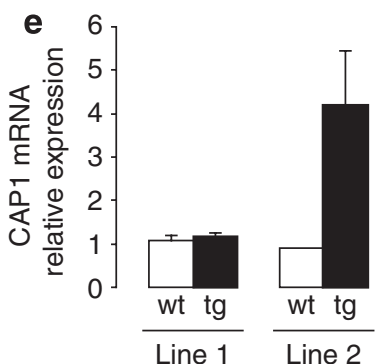

f

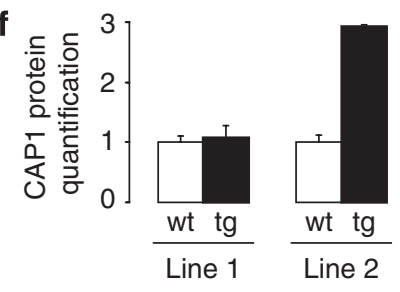

CAP1/Prss8 $=37 \mathrm{kDa}$

Figure 1 | Generation of K14-CAP1/Prss8 transgenic mice. (a) Scheme of the K14-CAP1/Prss8 construct containing the mouse CAP1/Prss8 coding sequence (cDNA, g.i. 19111159), the human K14 promoter, the rabbit $\beta$-globin intron and the human growth hormone polyadenylation signal (polyA). Restriction sites used for isolation of the transgene (Clal, Notl) and for Southern blot analysis (EcoRV) are indicated. For transgene-specific genotyping, primers 1 and 2, and for reverse transcriptase (RT)-PCR, primers 3 and 4 (arrows), were used. (b) Detection of K14-CAP1/Prss 8 transgenic mice (line 1 and line 2) following Southern blot analysis (wild type, wt, $12 \mathrm{~kb}$; transgenic, tg, $3.6 \mathrm{~kb}$ ). (c) PCR genotyping using transgene-specific primers 1 and 2 (see a) and myogenin-specific primers (myo; endogenous control). (d) Immunofluorescence (green) shows transgenic CAP1/Prss 8 expression in the basal layer of the epidermis in K14-CAP1/Prss8 transgenic mice. The white dotted line represents the basal membrane. Nuclei were counterstained with DAPI (blue). The white bar indicates $20 \mu \mathrm{m}$; (b-d) $n \geq 4$ mice/genotype. (e) CAP1/Prss 8 gene expression in the skin was determined by quantitative RT-PCR analysis and normalized to $\beta$-actin. Line 1: $n=3$ animals/genotype. Line 2: $w t, n=2$ (data: 0.92 and 0.87 ) and tg, $n=4$ animals analysed. (f) CAP1/Prss 8 protein expression was quantified by western blotting and loading was controlled by $\beta$-actin. Line $1: n=3$ animals per genotype. Line $2: n=4$ animals per genotype. All data are presented as mean \pm s.e.m.

exclusively in the stratum basale and hair follicles, was now detected in all nucleated epidermal cell layers. The expression of keratin-6, normally present only in hair follicles, was also detectable in interfollicular keratinocytes (Fig. 3a; Supplementary Fig. S1g), consistent with epidermal hyperplasia.

To test the integrity of intercellular tight junctions in the granular layer of the epidermis, we injected NHS-LC-biotin (600 Da) into the dermis and subsequently visualized its diffusion on sections stained with fluorescently conjugated streptavidin. NHS-LC biotin diffused freely between cells up to the second-last nucleated layer of the epidermis with no discernable difference between transgenic mice and littermate controls (Fig. 3a). Thus, the epithelial barrier within the granular layer appeared fully functional at least for molecules $\geq 600 \mathrm{Da}$.

The extracellular lipid barrier in the stratum corneum consists mainly of ceramides, free fatty acids and cholesterol present in a unique and stoichiometric composition. The ceramides are preferentially composed of probarrier lipids glucosylceramide, sphingomyelin and cholesterol sulphate ${ }^{26}$. Ceramide levels were significantly higher in transgenic mice (Fig. 3d; Supplementary Fig. S1j), and more ceramide forms with longer fatty acids were present as seen by ceramide fractionation and densitometric quantification (Cer(C26)-NS, Cer(C26-AS), Cer(C26-NH) and Cer(EOS); Supplementary Table S1), as well as more ceramide precursors glucosylceramide and sphingomyelin. Cholesterol sulphate levels were nearly 1.8-fold higher than that of controls (Fig. 3e; Supplementary Fig. S1k). Covalently bound lipids, which are also important for skin barrier function $^{27}$, were then separated into $\omega$-hydroxylated fatty acid and Cer(OS), showing that Cer(OS) levels were only $6.3 \%$ of that of control mice in line 2 (Fig. 3f) and 14\% of that of control mice in line 1 (Supplementary Fig. S11).

The hydrophobic water-protective barrier of the skin consisting of lipids originates from lamellar bodies secreted by keratinocytes of the granular layer ${ }^{28}$. Electron microscopy analyses revealed that secretion of lamellar bodies is diminished in the transgenic epidermis and that numerous lamellar body-like inclusions are present in transgenic corneocytes (Fig. 3g). The stratum granulosumstratum corneum interface appeared to be widened in transgenic mice, containing less vesicular lamellar bodies and more electrondense amorphous material. The process of corneodesmosome degradation and stratum corneum desquamation was delayed in the transgenic epidermis relative to control epidermis (Fig. 3g). Thus, defective epidermal barrier function in K14-CAP1/Prss 8 transgenic mice is likely to originate from altered epidermal proteinlipid composition.

Itching and inflamed skin in K14-CAP1/Prss8 mice. Transgenic animals surviving till adulthood frequently exhibited skin lesions (Fig. 4a; Supplementary Fig. S1m) possibly caused or aggravated by increased scratching behaviour (Fig. 4b; Supplementary Fig. S1n), which was evident after weaning and persistent throughout life. Lesions were sometimes accompanied by inflammation and swelling of regional lymph nodes, which were found to be enriched in plasma cells (Fig. 4a; Supplementary Fig. S1m).

Epidermal thickening and increased dermal cellularity (Fig. 2c) are often observed in mice with skin inflammation ${ }^{29}$. To address the characteristics and the origin of the inflammatory phenotype and how it correlated with epidermal hyperplasia, barrier dysfunction 
a
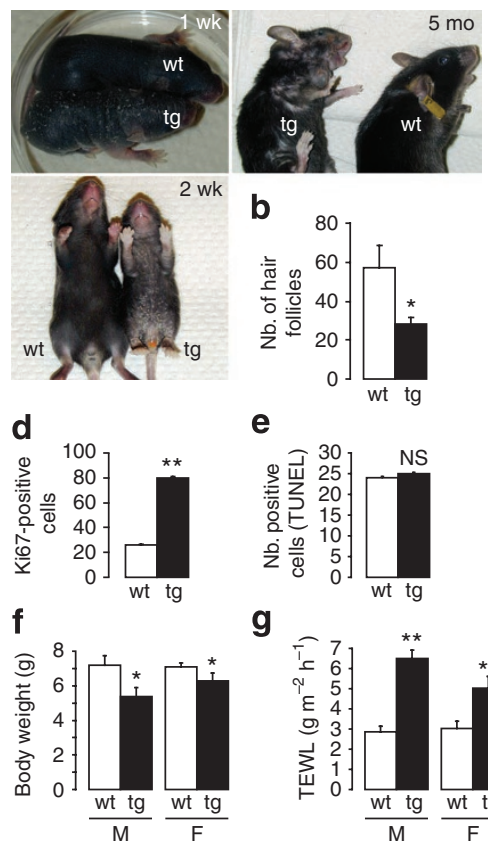

b

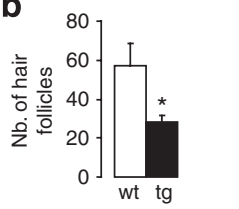

e

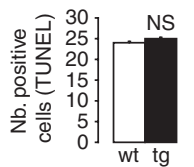

g

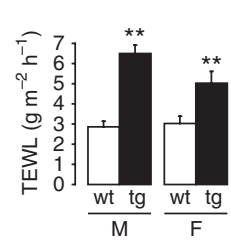

C
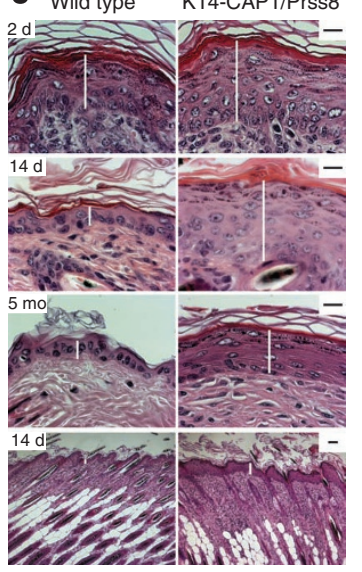

h

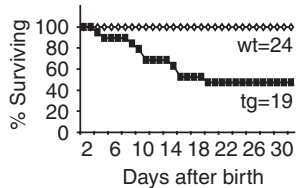

Figure 2 | Phenotype of K14-CAP1/Prss8 transgenic mice.

(a) Macroscopic appearance of transgenic mice and littermate controls at 1 week ( 1 wk), 2 weeks ( 2 wk) and 5 months ( 5 mo) of age. (b) Quantification of the number ( $\mathrm{Nb}$.) of hair follicles in transgenic versus control skin. $n=3$ mice per genotype, ${ }^{\star} P<0.05$. (c) Haematoxylin and eosin analyses of 2-day (2 d)-, 2-week (14 d)- and 5-month (5 mo)-old K14CAP1/Prss 8 mice compared with wild-type littermates. White bars indicate the thickness of the epidermis. Scale bars indicate $20 \mu \mathrm{m} . n=3$ mice per genotype. (d) Quantification of the number of Ki67-positive cells in the epidermis of 2-week-old animals. (e) Quantification of the number ( $\mathrm{Nb}$.) of cells undergoing apoptosis in the epidermis of K14-CAP1/Prss8 versus wildtype littermates ( $n=3$ mice per genotype, NS: not significant). (f) Body weight measurements of 2-week-old male (M) and female (F) transgenic mice and littermate controls, ${ }^{\star} P<0.05$. (g) Transepidermal water loss (TEWL) measurements of male and female transgenic mice. $n \geq 4$ animals per group, ${ }^{\star \star} P<0.01$. (h) Survival curves of K14-CAP1/Prss 8 versus wild-type littermates. All data are presented as mean \pm s.e.m.

and itching, we explored the expression of cytokines and procytokines in the skin of K14-CAP1/Prss 8 transgenic mice. Interleukin$1 \alpha$ (IL-1 $\alpha$ ), interleukin $1 \beta$ (IL-1 $\beta$ ), thymic stromal lymphopoietin (TSLP) and the extracellular matrix remodelling enzyme matrix metalloproteinase-9 (MMP9) were upregulated relative to littermate controls (Fig. 4c). Histological staining of 2-week-old transgenic skin showed no evidence of parasites, blood cells (Giemsa staining), lymphocytes or mucopolysaccarides, and hence no fungal infections (periodic acid-Schiff). However, S100, a common antigen for dendritic cells and macrophages, and the macrophage-specific antigen F4/80 (ref. 30) were both more abundant in the skin of K14CAP1/Prss 8 transgenic mice than in that of littermate controls. Consistent with the increase in antigen-presenting cells, CD3-positive T cells were also more abundant in the skin of K14-CAP1/Prss 8 transgenic mice (Fig. 4d,e). Fluorescence-activated cell sorting (FACS) analyses of 6-day-old pups revealed an increase in the number of CD11c- (a marker for dendritic cells ${ }^{31}$ ), F4/80- and CD3-positive cells, and showed abnormal presence of CD3-positive/Vg3-negative $\mathrm{T}$ cells ${ }^{32}$ in the K14-CAP1/Prss8 transgenic skin already at this time (Fig. 4f). Two-day-old K14-CAP1/Prss 8 transgenic pups also had increased numbers of S100-positive cells (Fig. 4g,h), but there was not yet a difference in F4/80 staining at this time (Fig. 4g). This suggests an inflammatory phenotype in the skin of transgenic mice with very early onset, and a potential initiating role for dendritic cells in this process.

As dendritic cell-mediated skin inflammation has been linked to TSLP production by keratinocytes ${ }^{33}$, we further investigated TSLP expression in the skin by real-time PCR. Although no difference was seen at embryonic day 17.5 (E17.5) or at postnatal day 1 (P1), a dramatic increase in TSLP expression was observed in transgenic skin at P2, P7 and P14 (Fig. 4i). No difference in TEWL or body weight was observed at P1, P2 and P5 (Fig. 4j,k), indicating that the defective barrier function and decrease in body weight might be secondary to epidermal hyperplasia and skin inflammation. Primary keratinocytes derived from transgenic and control littermates at P2 showed increased TSLP expression (Fig. 4l) and proliferation rates (Fig. $4 \mathrm{~m}$ ), suggesting that hyperplasia and inflammation might both originate in the transgenic keratinocytes. Transcripts for proinflammatory mediators IL- $1 \alpha$, IL-1 $\beta$ and MMP9 were barely or not at all detectable in the same cells (Fig. 4l). Thus, chronic skin inflammation, characterized by immune cell infiltration and expression of procytokines and cytokines, occurs early in parallel to epidermal hyperplasia in K14-CAP1/Prss 8 transgenic mice. Although apparently not causative, barrier dysfunction and itching may later aggravate these phenotypes.

Ichthyosis and itching in $\mathrm{Grhl}^{\mathrm{PAR2} /+}$ mice. To probe the contribution of PAR2 signalling to skin disease, we addressed whether increased expression of PAR2 in mouse skin might induce a pathological transformation similar to what had been observed with altered CAP1/Prss8 activity. We inserted a cassette consisting of the mouse PAR2 coding sequence followed by an internal ribosomal entry site and the lacZ reporter gene at the start codon of the grainyhead-like-3 (Grhl3) gene (Grhl3 ${ }^{\text {PAR2/+ }}$ ) by homologous recombination (Fig. 5a,b). The Grhl3 locus drives the expression of PAR2 throughout the epithelial ectoderm from mid-gestation onwards $\mathrm{s}^{1,34,35}$. Consistent with simultaneous interruption of the Grhl3 gene, mice with PAR2 inserted in both alleles ( $G r h l 3^{\text {PAR2/PAR2 }}$ ) died perinatally with spina bifida $^{34}$. Therefore, Grhl3 ${ }^{\text {PAR2/+ }}$ mice were used throughout this study for transgenic PAR2 overexpression. Importantly, mice carrying one functional allele of the Grhl3 gene $\left(\mathrm{Grhl}^{+/-}\right)$do not exhibit phenotypic differences compared to wt controls ${ }^{34}$, and knock-in of the Cre recombinase into the Grhl3 gene locus also affects Grhl3 gene expression, but does not trigger skin pathology ${ }^{16}$.

The expression of the Grhl $3^{\text {PAR2/+ }}$ allele, as monitored by lacZ staining, was found predominantly in the suprabasal layers of the epidermis (Fig. 5c). Although Grhl $3^{\text {PAR2/+ }}$ mice appeared normal at birth, they started to exhibit a scaly skin, mostly evident on the tail, and epidermal hyperplasia from 2 weeks onwards (Fig. 5d). Similar to K14-CAP1/Prss 8 transgenic mice, Grhl $3^{P A R 2 /+}$ animals displayed increased scratching behaviour in adulthood (Fig. 5e) and severe skin lesions associated with occasional lymph node swelling (Fig. 5f). Notably, scratching behaviour was not observed in young mice or in adult mice without lesions, and did not appear to precede lesion formation. The common features in the phenotype of $\mathrm{Frhl}^{P A R 2 /+}$ and K14-CAP1/Prss 8 transgenic mice support a possible role for PAR2 in CAP1/Prss8-induced skin pathology.

PAR2 deficiency rescues K14-CAP1/Prss8-induced skin defects. To address whether CAP1/Prss8 can trigger PAR2 activation in vivo and to experimentally test whether the similarities between Grhl $3^{\text {PAR2/+ }}$ and K14-CAP1/Prss 8 transgenic animals were due to excessive PAR2 activation in both models, we crossed K14-CAP1/ Prss 8 transgenic mice from line 2 with mice constitutively and globally deficient in PAR2 $\left(P A R 2^{-/-}\right)$that do not exhibit obvious skin abnormalities ${ }^{36}$. Mice carrying the K14-CAP1/Prss 8 transgene that were either wt (K14-CAP1/Prss8) or heterozygous mutant for PAR2 (K14-CAP1/Prss8:PAR2 ${ }^{+/-}$) displayed scaly skin with epidermal 

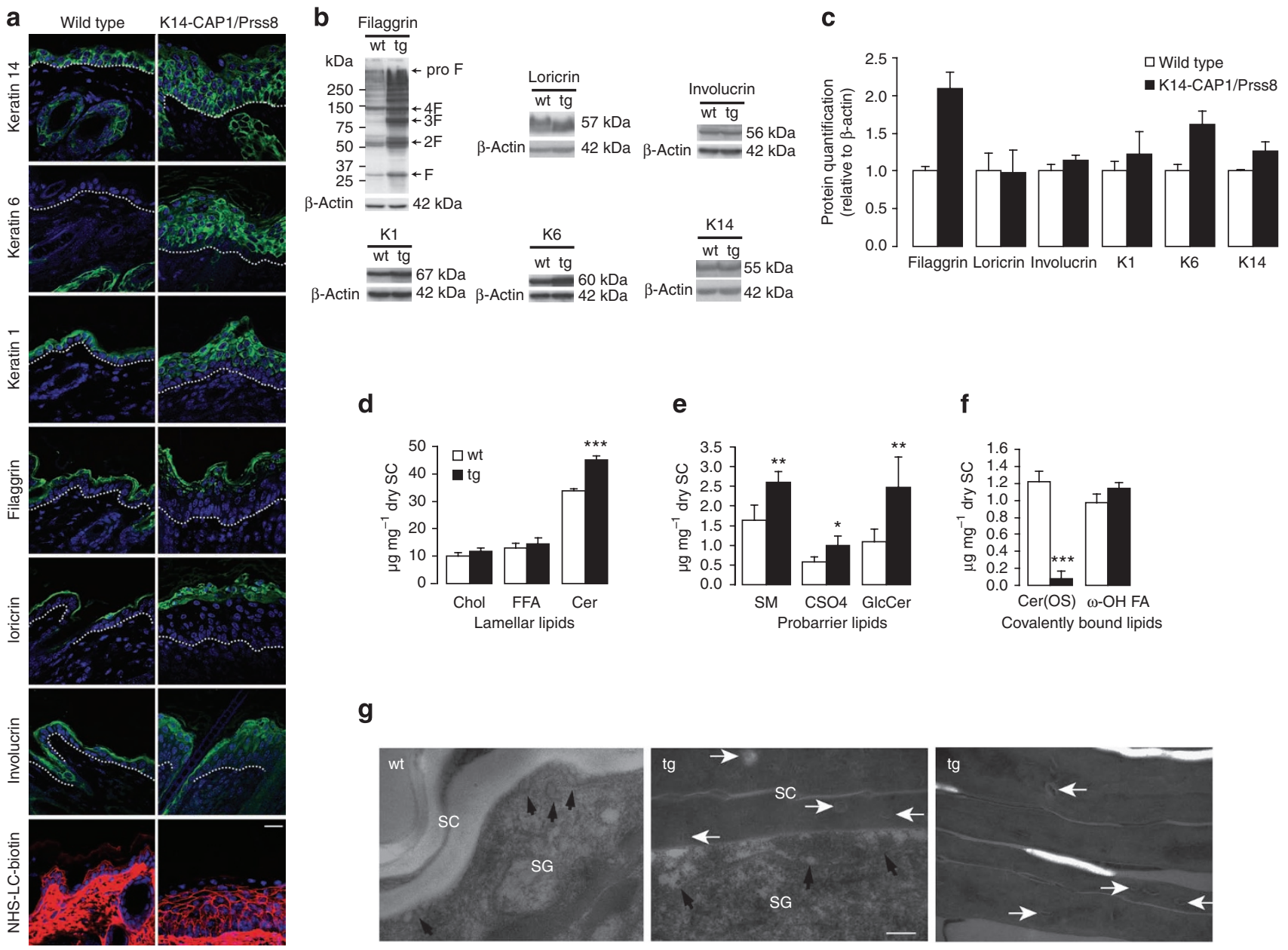

d

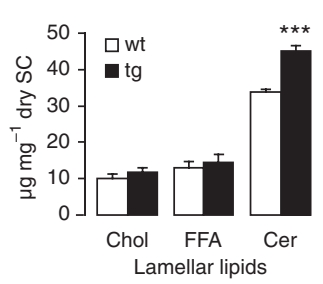

g

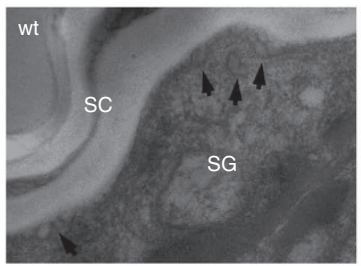

e

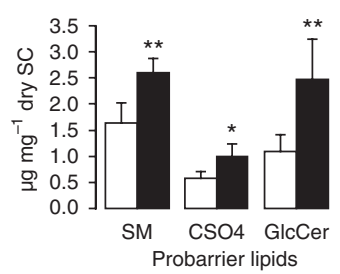

f
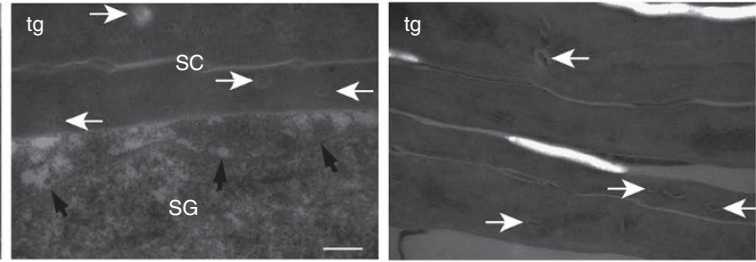

Figure 3 | Altered protein and lipid composition in K14-CAP1/Prss8 epidermis. (a) Epidermal differentiation markers (keratin-14, -6, -1, filaggrin, loricrin and involucrin) as present (green) in both wild-type and transgenic mice. Dotted lines indicate basal membrane. Below: tight junction permeability assay using NHS-LC-biotin (red). Nuclei are counterstained with DAPI (blue). Scale bar represents $20 \mu \mathrm{m} ; n=3$ mice per group. (b) Western blot analyses demonstrate the expression of filaggrin, loricrin, involucrin, keratin-1 (K1), keratin-6 (K6) and keratin-14 (K14) in skin of transgenic and control mice. Loading is controlled by $\beta$-actin and proteins are quantified in (c), $n \geq 4$ animals per group. (d) Analysis of unbound stratum corneum lipids by thin layer chromatography in transgenic versus littermate controls. Cholesterol (Chol), ceramide (Cer), free fatty acids (FFA). (e) Analysis of probarrier lipids sphingomyelin (SM), cholesterol sulphate $\left(\mathrm{CSO}_{4}\right)$ and glucosylceramide (GlcCer). (f) Covalently bound lipids: In K14-CAP1/Prss8 transgenic mice, ceramide (OS) levels (Cer(OS)) were reduced to $6.3 \%$ of controls. (Chl: cholesterol, FFA: free fatty acids, $\omega$-OH FA: $\omega$-hydroxy fatty acids), $n \geq 3$ mice per group; (c-f) All data are presented as mean \pm s.e.m. ${ }^{\star} P<0.05,{ }^{\star \star} P<0.01,{ }^{\star \star \star} P<0.001$. (g) Electron microscopy of skin of K14-CAP1/Prss8 2-week-old transgenic $(n=4)$ and wild-type littermates $(n=3)$ depicting interface between stratum granulosum (SG) and stratum corneum (SC; left, middle panel). Lamellar bodies are shown in the SG (black) and SC (white arrows). Right panel: intermediate portion of hyperkeratotic scales in transgenic mice. Scale bar represents $200 \mathrm{~nm}$.

hyperplasia (Fig. 6a). In contrast, no scaling, epidermal hyperplasia or premature lethality was observed in K14-CAP1/Prss 8 transgenic mice that were homozygous mutant for PAR2 (K14-CAP1/Prss8: $P A R 2^{-/-}$, Fig. 6a and Table 1). Despite the absence of PAR2, these mice still expressed the K14-CAP1/Prss 8 transgene (Fig. 6a,b). The rescue was also evident functionally, as K14-CAP1/Prss8:PAR2-/mice exhibited TEWL in the same range as that of wt controls but significantly different from that of K14-CAP1/Prss8:PAR2 $2^{+/+}$littermates (Fig. 6c). Moreover, whereas K14-CAP1/Prss 8 mice displayed a significantly lower body weight compared with controls, the K14CAP1/Prss8:PAR2 $2^{-/-}$mice were indistinguishable from littermate controls in this regard (Fig. 6d). Surprisingly, heterozygosity for PAR2 was sufficient to reverse the increased water loss and reduced body weight observed in K14-CAP1/Prss 8 transgenic mice, despite persistence of ichthyotic and hyperplastic phenotypes (Fig. 6c,d). Moreover, expression levels of inflammatory markers IL-1 $\alpha$, IL-1 $\beta$, TSLP and MMP9, as well as of macrophage and dendritic cell markers anti-F4/80 and anti-S100, were indistinguishable from control levels in K14-CAP1/Prss8:PAR2 ${ }^{-/-}$animals (Figs $4 \mathrm{c}$ and $6 \mathrm{e}, \mathrm{f}$ ). K14-CAP1/Prss8:PAR2 ${ }^{+/}$mice manifested an intermediate phenotype, suggesting a dose-dependent effect of PAR2. Thus, absence of PAR2 completely rescued hyperplasia, barrier dysfunction, inflammation and ichthyosis caused by altered CAP1/Prss8 expression in the skin, establishing PAR2 as a pivotal mediator of K14-CAP1/ Prss8-driven skin pathology in this model.

Expression of CAP1/Prss8 and PAR2 in human skin. CAP1/Prss8 immunodetection on skin cross-sections from four healthy controls and from five acute, two atopic and three chronic dermatitis patients showed defined localization of CAP1/Prss8 in the granular layer of the human epidermis (Fig. 7) similar to CAP1/Prss8 expression in murine skin ${ }^{8}$. In healthy controls and acute dermatitis patients, CAP1/Prss8 was localized both intracellularly and at the plasma membrane. In patients with chronic and atopic dermatitis, 

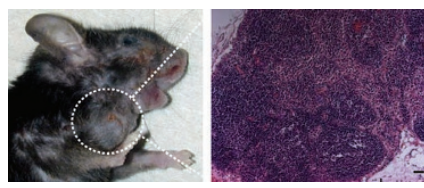

b

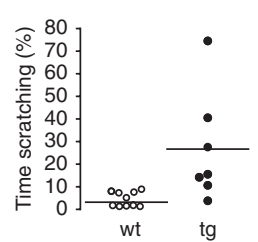

e

f

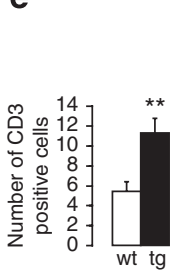

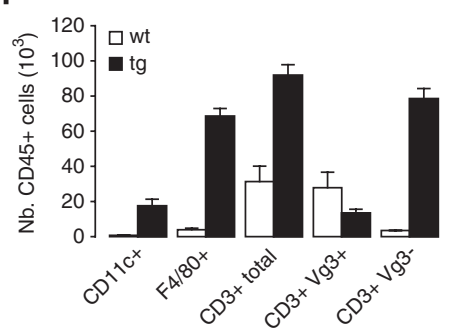

C

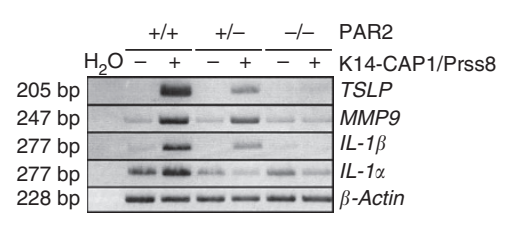

g

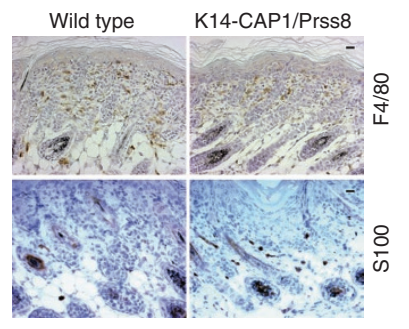

d

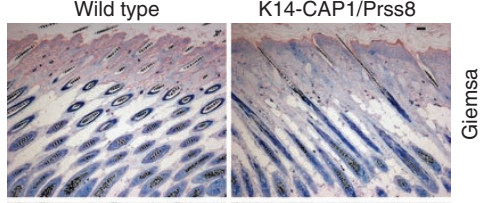

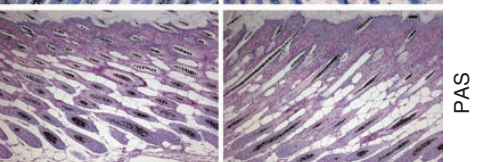
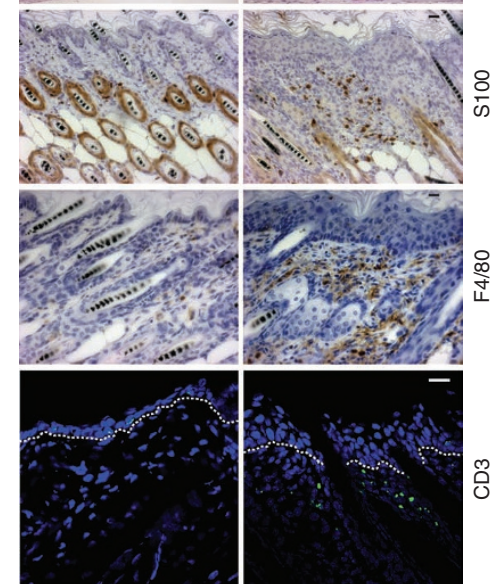

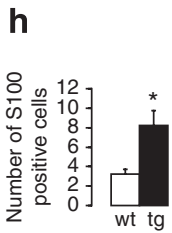
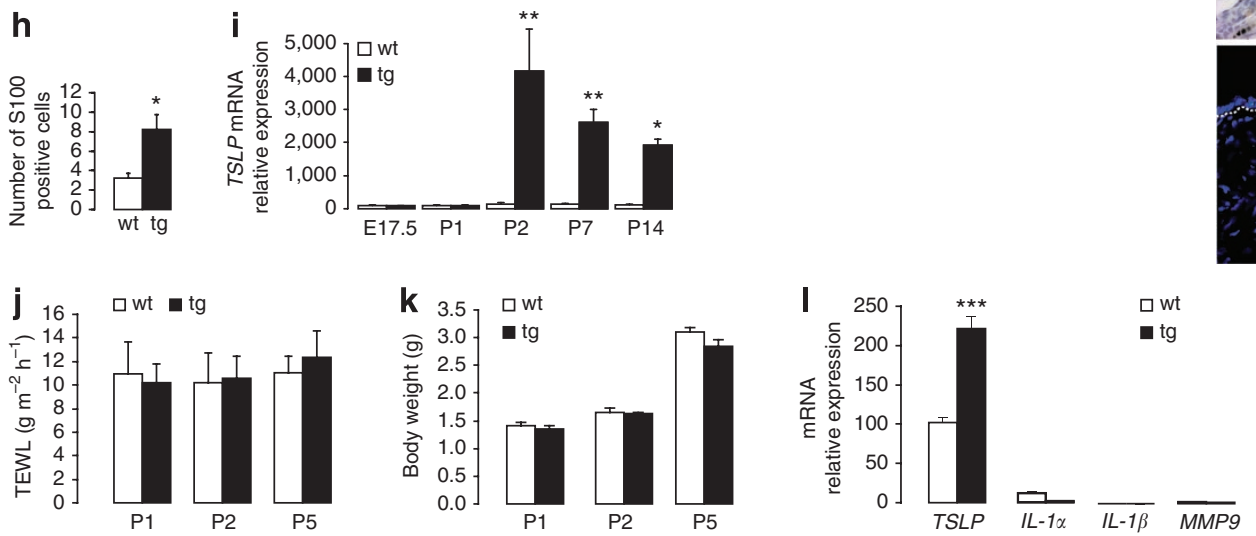

Figure 4 | K14-CAP1/Prss8 mice exhibit itching and severe skin inflammation. (a) Skin injuries with open wounds and lymph node inflammation (haematoxylin and eosin staining, bar represents $20 \mu \mathrm{m}$ ) in a representative 7-month-old transgenic mouse. (b) Dot plot indicating the duration of the scratching behaviour expressed in percentage. Each dot represents a single event per animal. Bars indicate the average of the time spent scratching, $P<0.01$. (c) Semiquantitative RT-PCR analysis of TSLP, MMP9, IL-1 $\beta$ and $I L-1 \alpha$ (30 cycles) in transgenic versus wild-type skin. The reaction is controlled by detection of $\beta$-actin (25 cycles). Water was used as negative control. Data are representative of $n=3$ mice per genotype. (d) Giemsa, periodic acidSchiff staining and S100, F4/80 and CD3 labelling in skin of 2-week-old wild-type and K14-CAP1/Prss8 transgenic mice. Pictures are representative of $n=3$ animals per genotype. Bars represent $20 \mu \mathrm{m}$. (e) Quantification of the number of CD3-positive cells in transgenic versus wild-type skin. $n=3$ mice

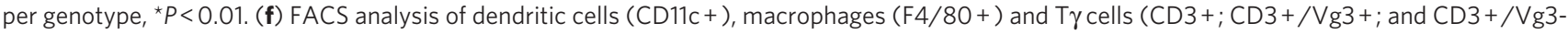
) in skin of 6-day-old pups ( $n=3$ mice per genotype). (g) F4/80 and S100-positive cells in skin of 2-day-old transgenic and littermate controls. Bar represents $20 \mu \mathrm{m}$; pictures are representative of $n=3$ mice per genotype. (h) Quantification of the number of S100-positive cells in 2-day-old transgenic and littermate animals. $n=3$ mice per genotype, ${ }^{\star} P<0.05$. (i) TSLP quantitative RT-PCR analyses of wild-type and transgenic skin in 2 -day-old pups ( $n \geq 3$ mice per group, $\left.{ }^{\star} P<0.05,{ }^{\star}{ }^{\star} P<0.01\right)$. (j) TEWL and body weight (k) measurements at P1, P2 and P5 ( $n \geq 4$ mice per group). (I) Quantitative RT-PCR examination of TSLP,IL1 $\alpha, I L 1 \beta$ and MMP9 in transgenic primary keratinocytes, ${ }^{\star \star \star} P<0.001$. (m) Quantification of cell growth assessed in primary

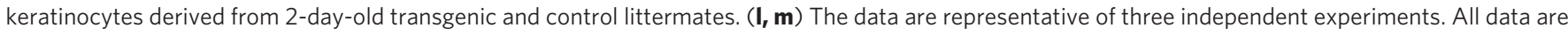
presented as mean \pm s.e.m.

CAP1/Prss8 appeared to be predominantly expressed at the plasma membrane. PAR2 expression was seen in suprabasal keratinocytes in the same samples and appeared to be more extensive in chronic and atopic dermatitis patients, following hyperplasia. It is thus conceivable that differential expression of CAP1/Prss8 and/or PAR2 in diseased versus healthy skin may contribute to the pathogenesis of these disorders.

\section{Discussion}

Altered activity of serine proteases ${ }^{4,7,8,10,37}$ and serine protease inhibitors ${ }^{5,9,38}$ can severely compromise skin homeostasis in mice and humans. In this study we used mouse models to demonstrate that increased expression of either the membrane-tethered serine protease CAP1/Prss8, or PAR2, a candidate downstream effector, is sufficient to induce skin disease in mice and that CAP1/Prss8elicited pathogenesis is fully dependent on PAR2.

Transgenic K14-CAP1/Prss 8 mice exhibited severe ichthyosis, hyperplasia, epidermal barrier defects and inflammation. Intriguingly, lack of one PAR2 allele associated with CAP1/Prss8 overexpression was sufficient to completely reverse the increased TEWL and body weight loss, but not ichthyosis and hyperplasia, suggesting that barrier dysfunction was not secondary to epidermal hyperplasia. Increased proliferation and TSLP production in primary keratinocytes isolated from K14-CAP1/Prss 8 transgenic mice suggested that hyperplasia and inflammation were both, at least in part, directly triggered by a protease signalling cascade in keratinocytes, supporting a cell-autonomous phenotype. TSLP production by epithelial cells has been shown to trigger dendritic cell-mediated 
a
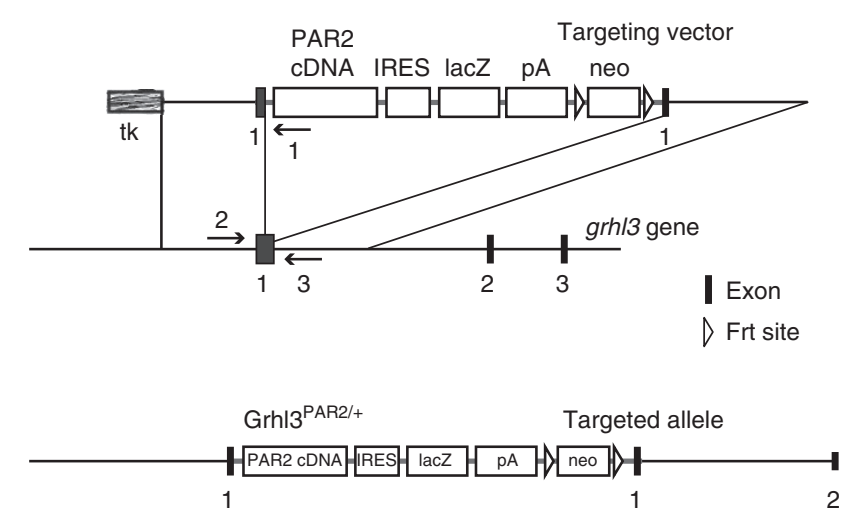

b

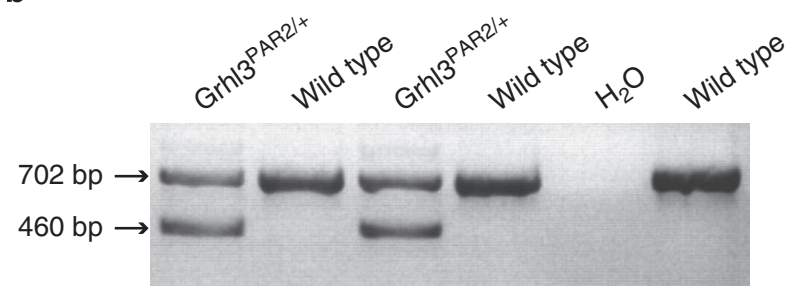

C

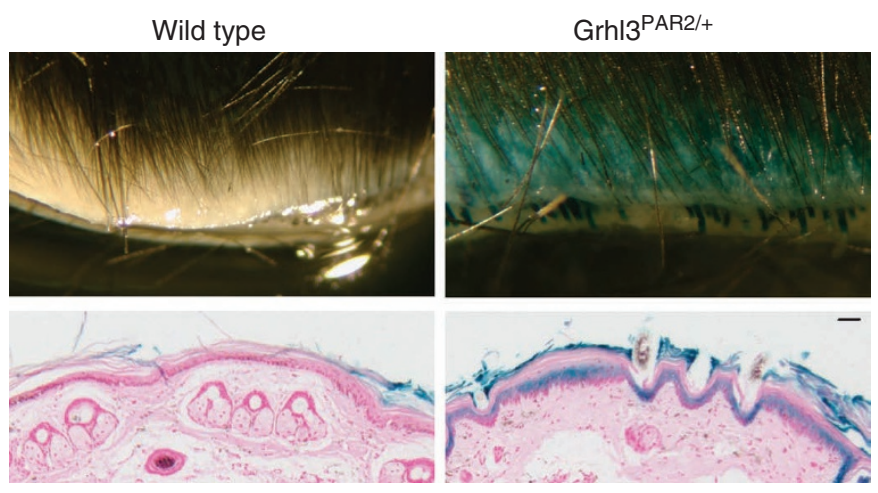

d
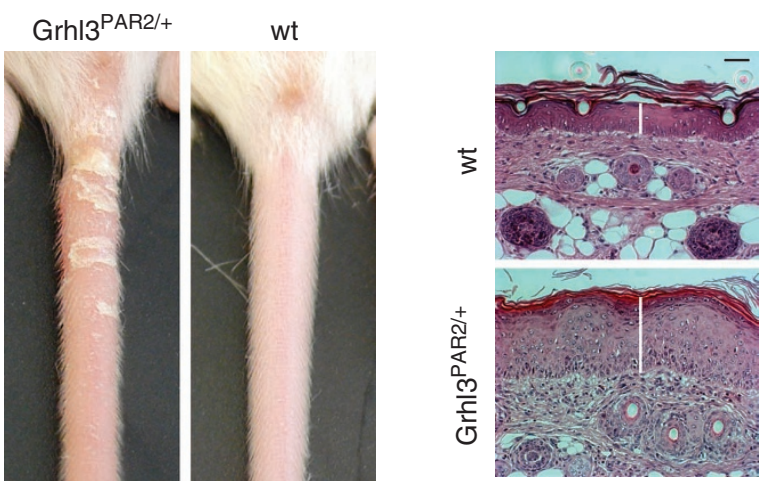

Grhl3 ${ }^{\mathrm{PAR} 2 /+}$

wt

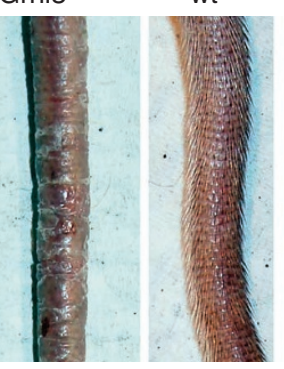

wt

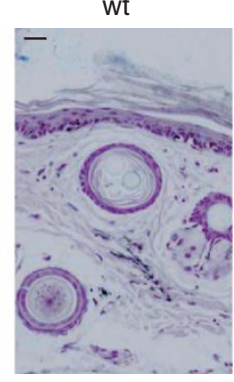

Grhl3 $3^{\text {PAR2/+ }}$

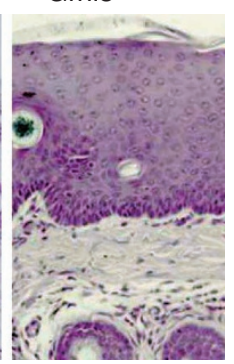

e

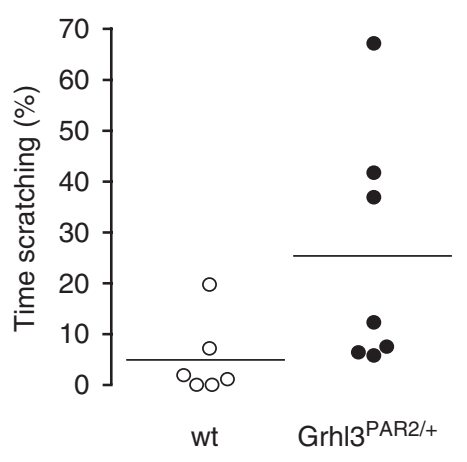

f
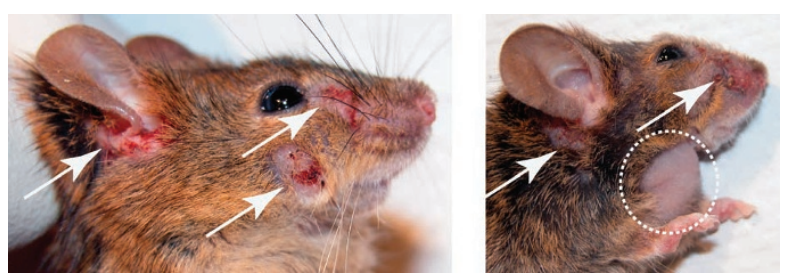

Figure 5 | Generation and characterization of Grhl/ PAR2/+ transgenic mice. (a) Scheme of the Grh/3PAR2/+ knock-in targeting vector, part of the targeted Grhl3 gene locus and the resulting targeted allele. Exons (black boxes), transgenic sequences (from the left, white boxes: mouse PAR2 coding sequence [PAR2 cDNA], internal ribosome entry site [IRES], lacZ coding sequence [lacZ], poly A signal [pA], neomycin cassette [neo]) and Frt sites (open triangles) are shown. Primers 1, 2 and 3 used for PCR genotyping are represented (arrows). Primers 1 and 2 amplify the mutant Grh/ ${ }^{P A R 2}$ allele, and primers 2 and 3 amplify the endogenous Grh/3 allele. (b) PCR-based genotyping of Grh/3PAR2+ transgenic mice. Amplified fragments using specific primers reveal the mutant (460 bp) and endogenous (702 bp) Grh/3 alleles. (c) $\beta$-Galactosidase staining (light blue) on skin autopsy samples and on skin sections from Grh/3PAR2/+ mice counterstained with neutral red (pink) of the respective genotypes. Bar represents $10 \mu \mathrm{m}$. (d) Phenotypic appearance and haematoxylinand eosin-stained skin of Grh/3PAR2/+ mice versus control littermates at 2 weeks of age (top panel) and in adulthood (lower panel). Scale bars represent $20 \mu \mathrm{m}$. (e) Dot plot indicating the percentage of monitoring time spent scratching or grooming. Bars indicate the average of the time spent scratching. Each dot represents a single animal $(P<0.05)$. (f) Skin injuries (white arrows) become evident in adult Grh/3PAR2/+ transgenic mice with occasional swelling of regional lymph nodes (dotted circle). (c, $\mathbf{d}, \mathbf{f}) n \geq 3$ mice per group.

inflammation ${ }^{33}$, and it is well established that dendritic cells migrate from inflamed peripheral tissues to the closest draining lymph node to orchestrate adaptive immune responses ${ }^{39}$. PAR2 signalling was recently shown to promote dendritic cell trafficking to lymph nodes and subsequent T-cell activation ${ }^{40}$. In our K14-CAP1/Prss 8 model, CD11c- and S100-positive dendritic cells were found to be more abundant in the skin, supporting a potential role for TSLP expression in immune cell recruitment and activation. Consistent with these findings, CAP1/Prss8 transgenic skin exhibited an increase in CD3-positive T cells, as demonstrated by both immunohistochemistry and FACS quantification. Taken together, these data suggest a possible CAP1/Prss8-PAR2-TSLP cascade in which TSLP, 

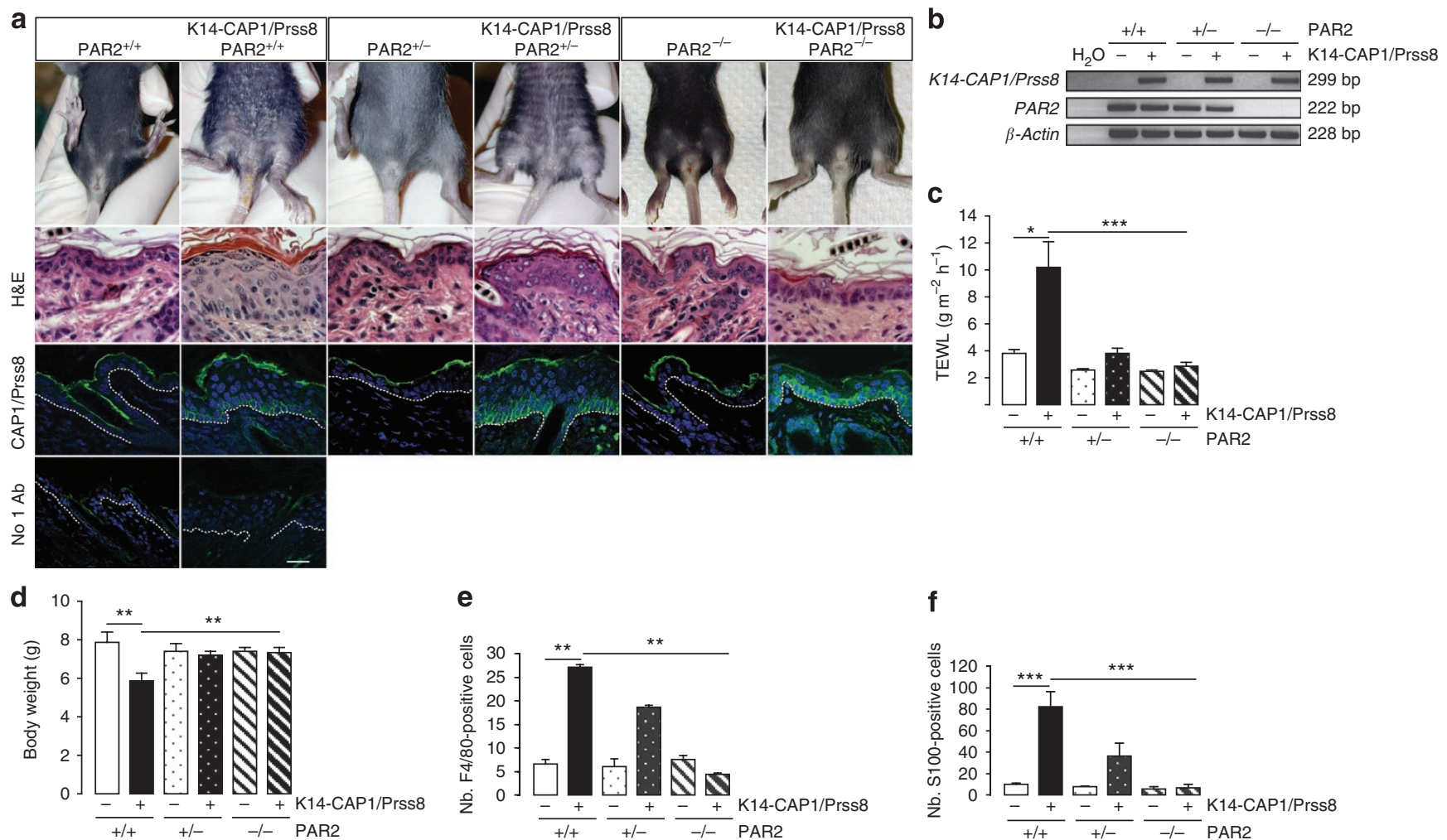

Figure 6 | Ichthyosis and inflammation are absent in K14-CAP1/Prss8:PAR2 ${ }^{-/-}$mice. (a) Macroscopic appearance of 2-week-old animals. H\&E: haematoxylin and eosin staining of skin. Immunofluorescence (green) shows transgenic CAP1/Prss8 expression at the basal layer in K14-CAP1/Prss8: PAR2 ${ }^{+/+}$, K14-CAP1/Prss8:PAR2 ${ }^{+/-}$and K14-CAP1/Prss8:PAR2 ${ }^{-/-}$transgenic mice. Below: negative control (omission of primary antibody, no 1Ab). Nuclei were counterstained with DAPI (blue), $n \geq 3$ mice per group. Bar represents $20 \mu \mathrm{m}$. (b) RT-PCR analysis demonstrates expression of the CAP1/Prss 8 transgene in K14-CAP1/Prss8:PAR2 ${ }^{+/+}$, K14-CAP1/Prss8:PAR2 ${ }^{+/-}$and K14-CAP1/Prss8:PAR2 ${ }^{-/-}$transgenic mice, and absence of PAR2 gene expression in $P A R 2^{-/-}$animals. $\beta$-actin was used to control cDNA, and $\mathrm{H}_{2} \mathrm{O}$ provided negative control. The blot is representative of three animals analysed per group. (c) Transepidermal water loss and body weight analyses (d) in experimental and control animals, $n \geq 8$ mice per group. ${ }^{\star} P<0.05,{ }^{\star \star} P<0.01,{ }^{\star \star \star} P<0.001$. (e) Numbers (nb.) of F4/80- and (f) S100-positive cells evident in the skin of 2-week-old animals; $(\mathbf{e}, \mathbf{f}) n=3$ mice per genotype. ${ }^{\star \star} P<0.01$, ${ }^{\star \star \star} P<0.001$ All data are presented as mean \pm s.e.m.

Table 1 | PAR2 deficiency prevents the K14-CAP1/Prss8-induced phenotype in double-transgenic K14-CAP1/Prss8:PAR2-/- mice (line 2).

\begin{tabular}{|c|c|c|c|c|c|c|}
\hline $\begin{array}{l}\text { Genotype } \\
\text { Breeding pairs }\end{array}$ & $\begin{array}{c}\text { K14-CAP1/Prss8 } \\
\text { PAR }^{-/-} \\
\end{array}$ & $P_{A R^{-/-}}$ & $\begin{array}{c}\text { K14-CAP1/Prss8 } \\
\text { PAR }^{+/-} \\
\end{array}$ & PAR2 $^{+/-}$ & $\begin{array}{c}\text { K14-CAP1/Prss8 } \\
\text { PAR2 }^{+/+} \\
\end{array}$ & PAR2 $^{+/+}$ \\
\hline $\begin{array}{l}\text { K14-CAP1/Prss8 PAR2 }{ }^{+/-} \\
\times \text {PAR2 }^{+/-}, n=135\end{array}$ & 18 & 20 & 34 & 31 & 16 & 16 \\
\hline Expected, \% & 12.5 & 12.5 & 25 & 25 & 12.5 & 12.5 \\
\hline $\begin{array}{l}\text { K14-CAP1/Prss8 PAR2 }{ }^{+/-} \\
\times \text {PAR2 }^{-/-}, n=71\end{array}$ & 12 & 16 & 26 & 17 & - & - \\
\hline Expected, \% & 25 & 25 & 25 & 25 & - & - \\
\hline CAP1/Prss8 scaly skin phenotype & - & - & + & - & + & - \\
\hline Animals found dead & 0 & 0 & 0 & 0 & 6 & 0 \\
\hline
\end{tabular}

mobilized by CAP1/Prss8-elicited PAR2 activation on keratinocytes, stimulates dendritic cells that then recruit $\mathrm{T}$ cells to start an adaptive inflammatory response.

Increased scratching behaviour was documented in both Grhl3 ${ }^{P A R 2 /+}$ knock-in and K14-CAP1/Prss 8 transgenic mice. Itching sensation can be induced by dry, damaged and inflamed skin, and numerous epithelial and immune mediators can activate and sensitize sensory nerve endings and even modulate their growth (reviewed in ref. 41). However, there is also a body of evidence to suggest that PAR2 can function as a direct mediator of pruritus in humans ${ }^{20}$ and mice $^{23}$. Functional PAR2 is present on primary spinal afferents $^{42}$, and proteases might activate PAR2 on sensory nerves in the skin. Importantly, however, we aimed to drive PAR2 expression in epithelial cells, not in sensory nerves, and, as predicted from the expression pattern of Grhl3 (ref. 35), dorsal root ganglia or peripheral nerves are not targeted. Thus, although itching might increase 


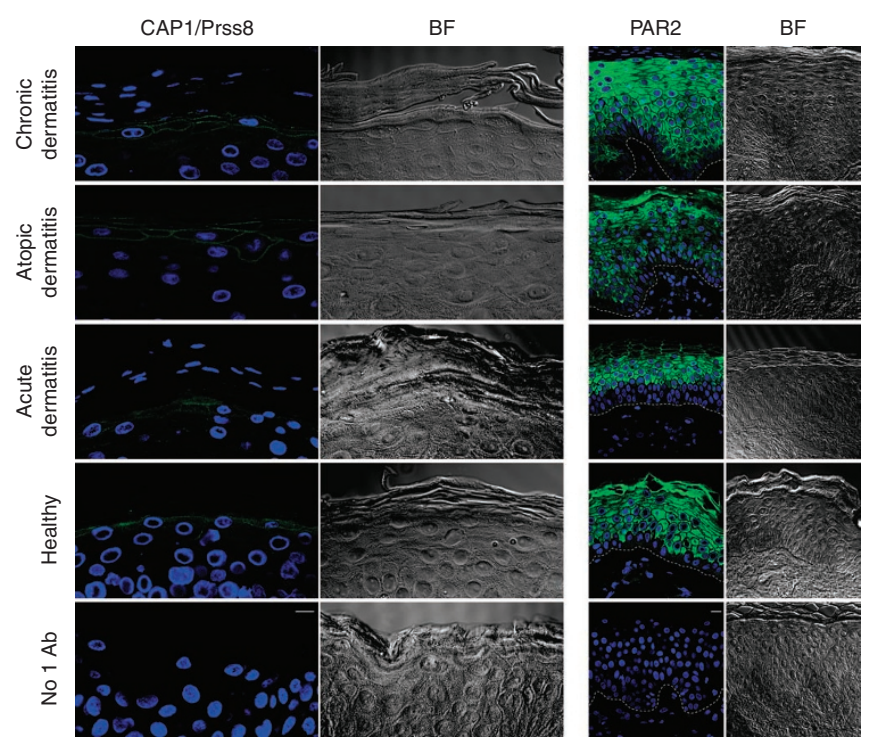

Figure 7 | Localization of CAP1/Prss8 and PAR2 in human epidermis. Immunohistochemistry of CAP1/Prss8 and PAR2, both in green, in human skin sections. Nuclei are counterstained with DAPI (blue). Bottom panel: parallel sections in which primary antibodies were omitted (negative control; No 1 Ab). The pictures are representative of biopsies analysed from two adult subjects with atopic dermatitis, five with acute dermatitis, three with chronic dermatitis and from four healthy controls. Dashed white lines represent epidermal/dermal junction. Scale bars represent $10 \mu \mathrm{m}$. BF: bright field.

lesion severity in older animals, and although neuronal PAR2 could be involved in itching sensation by paracrine activation of neuronal PAR2 in the CAP1/Prss8 model, itching did not appear to provoke the K14-CAP1/Prss 8 and Grhl3 $3^{\text {PAR2/+ }}$ phenotypes.

Exploring a potential role for CAP1/Prss8 as an activator of PARs during neural tube closure, it was recently observed that CAP1/ Prss8 was able to trigger PAR2-dependent signalling in a keratinocyte cell line. However, CAP1/Prss8 could not directly activate PAR2; it instead turned out that CAP1/Prss8-induced signalling in the systems studied was dependent on intermediate activation of the serine protease pro-CAP3/matriptase, which in turn was a remarkably potent and specific activator of PAR2 ${ }^{16}$. Constitutive CAP3/matriptase and skin-specific CAP1/Prss8 knockout mice exhibit similar phenotypes ${ }^{7,8,43}$ and CAP1/Prss 8 was found exclusively in its inactive form in CAP3/matriptase/MT-SP1-deficient skin, demonstrating that CAP3/matriptase also activates CAP1/ Prss8 in mouse skin. Hence, these findings strongly point to a more complex serine protease cascade, in which other components, such as additional serine proteases and serine protease inhibitors, could be involved. CAP3/matriptase has been found to be mutated in human autosomal recessive ichthyosis with hypotrichosis and ichthyosis in mice resulting from loss of function of HAI-1, a CAP3/ matriptase inhibitor ${ }^{9,44}$, can be rescued with low CAP3/matriptase activity ${ }^{9}$. This indicates that excessive CAP3/matriptase activity can indeed lead to skin disease, and enhanced CAP1/Prss8 expression could well contribute to the phenotype. Whereas ablation of PAR2 from LEKTI-null animals inhibited prenatal production of TSLP, but not cutaneous inflammation in adulthood ${ }^{45}$, ablation of CAP3/matriptase from LEKTI-deficient mice substantially ameliorated the phenotype of this mouse model of Netherton syndrome ${ }^{46}$. Thus, CAP3/matriptase clearly has effectors other than PAR2. Furthermore, the phenotype of K14-CAP1/Prss 8 transgenic mice differs from the K5-driven CAP3/matriptase overexpressing model ${ }^{10}$. Itching and severe skin lesions independent of tumour formations were not reported in $\mathrm{K} 5$-CAP3/matriptase transgenic mice ${ }^{10}$, and we never observed spontaneous tumour formation in CAP1/Prss8 transgenic animals, even when histopathologically followed up until their death. Finally, CAP1/Prss8 has been reported to have biological activity independent of its catalytic triad ${ }^{47,48}$; hence, we cannot exclude that CAP1/Prss8 elicits a protease cascade leading to PAR2 signalling by a cleavage-independent mechanism.

Besides functioning upstream of PAR2, as demonstrated here, CAP1/Prss8 is known to be involved in the activation of the highly amiloride-sensitive epithelial sodium channel $\mathrm{ENaC}^{49}$. Complete $\mathrm{ENaC}$ knockout mice die postnatally because of impaired lung fluid clearance ${ }^{50}$ and exhibit dehydration similar to skin-specific CAP1/Prss8-deficient animals ${ }^{8,51}$. Other epidermal effectors of CAP1/Prss8 are filaggrin and occludin, both of which are processed normally in ENaC-deficient skin $^{8,51}$. We therefore consider a contribution of $\mathrm{ENaC}$ to the K14-CAP1/Prss8-mediated skin phenotype as unlikely.

PAR2 has been implicated in inflammatory dermatosis ${ }^{17,52}$ and two natural mutations of CAP1/Prss 8 have been found as causative of skin defects in rodents ${ }^{53}$. In human epidermis we found that CAP1/Prss8 expression, mainly in the granular layer, appeared more concentrated to the plasma membrane in affected skin from patients with atopic and chronic dermatitis relative to skin from healthy controls, and was accompanied by enhanced PAR2 expression in the epidermis of the same affected subjects. Observations in our transgenic models should prompt further investigation into whether CAP1/Prss8, its inhibitors, PAR2 and its other activators are deregulated in diseased human skin. K14-CAP1/Prss 8 and Grhl3 $3^{\text {PAR2/+ }}$ mice may also serve as models to test the efficacy of protease inhibitors and/or PAR2 antagonists against ichthyosis, pruritus and inflammatory skin disorders.

\section{Methods}

Mice and primary cell culture. K14-CAP1/Prss 8 transgenic mice were generated by cloning mouse CAP1/Prss 8 cDNA (Genbank g.i. 19111159) into the pBHR2(SmaI) vector ${ }^{25,54}$ (See Supplementary Methods). The linearized vector was microinjected into B6D2F1 hybrid zygotes. Transgenic lines were maintained in the hemizygous state. Transgenic mice were genotyped by PCR and Southern blot analysis of genomic DNA extracted from tail biopsies ${ }^{55}$. Grhl3 $3^{\text {PAR2/+ }}$ knock-in mice were generated by targeting $129 \mathrm{X} 1 / \mathrm{SvJ}$-derived E14 ES cells using standard techniques, essentially as described for $\mathrm{Grhl}^{\mathrm{Cre} /+}$ mice $^{16,}$ except that Cre cDNA was replaced by mouse PAR2 cDNA. Further details of cloning are provided in Supplementary Information. The Grhl3 $3^{\text {PAR2/+ }}$ phenotype was observed in both C57BL6/J$129 \mathrm{X} 1 / \mathrm{SvJ}$ mixed and FVB/n strain backgrounds. Mice from both strains were used for the experiments. Experimental procedures and animal maintenance followed federal guidelines and were approved by local authorities.

Mouse epidermal keratinocytes were isolated from pups and cultured in vitro ${ }^{56}$ Cell proliferation was quantified using the Quick Cell Proliferation Testing Solution (GenScript) according to instructions provided by the manufacturer.

Measurement of scratching behaviour. For K14-CAP1/Prss 8 mice and littermate controls, simultaneous experiments on three mice in three individual cages were conducted in the absence of investigators. Mice could not see each other during the experiment. The mice were videotaped for 15-20 min for later quantification of scratching behaviour. One scratch was considered as lifting of a limb towards the body with subsequent replacement of the limb on the bedding. For Grhl3 $3^{\text {PAR2/+ }}$ mice and littermate controls, mouse behaviour was recorded in the absence of investigators and the time spent grooming and/or scratching quantified in a 5 min time period and expressed as percentage of total time.

Immunofluorescence and histology. For paraffin-embedded sections: Slides were incubated with primary antibodies for $1 \mathrm{~h}$ at room temperature following rinsing with PBS. Antigen retrieval was performed for $10 \mathrm{~min}$ in TEG buffer. Slides were washed in $50 \mathrm{mM} \mathrm{NH}_{4} \mathrm{Cl}$ in PBS for $30 \mathrm{~min}$ and blocked by $1 \% \mathrm{BSA}$, $0.2 \%$ gelatine, $0.05 \%$ Saponin in PBS at room temperature for $10 \mathrm{~min}$, three times. Primary antibody was diluted in $0.1 \%$ BSA, $0.3 \%$ Triton X-100 in PBS, overnight at $4{ }^{\circ} \mathrm{C}$. Antibodies against keratin-14, keratin-1, keratin-6, involucrin, loricrin and filaggrin were purchased from Covance and diluted 1:1,000 or 1:4,000 (keratin-14). Affinity-purified CAP1/Prss8 rabbit anti-mouse antiserum ${ }^{57}$ was diluted 1:200. Rabbit polyclonal antibody PAR2 (H-99; sc-5597) was provided by Santa Cruz Biotechnology and diluted 1:1,000. Slides were rinsed three times for $10 \mathrm{~min}$ in PBS containing $0.1 \%$ BSA, $0.2 \%$ gelatine and $0.05 \%$ saponin at room temperature and the secondary antibody (Alexa Fluor 488, diluted 1:5,000) was diluted in $0.1 \%$ BSA, $0.3 \%$ Triton X-100 in PBS. Nuclei were counterstained with 4,6-diamidino-2- 
phenylindole (DAPI) $0.2 \mu \mathrm{g} \mathrm{ml}^{-1}$ in mounting media (Dako Schweiz AG). Staining was visualized using an LSM confocal microscope (LSM 510 Meta, Carl Zeiss MicroImaging Inc.). For cryosections: Tissue-Tek O.C.T.-embedded skin was fixed in $2 \%$ paraformaldehyde (PFA) in PBS and permeabilized with $0.1 \%$ SDS in PBS. After blocking with $2 \%$ BSA and $3 \%$ normal goat serum (NGS), sections were incubated with a fluorescein isothiocyanate-conjugated rat anti-mouse CD3 antibody (555274, BD Pharmingen, diluted 1:100) for $1 \mathrm{~h}$. LacZ staining: LacZ expression was detected by incubating the tissue at $30^{\circ} \mathrm{C}$ overnight in $0.1 \% \mathrm{X}$-gal, $5 \mathrm{mM}$ potassium ferricyanide, $5 \mathrm{mM}$ potassium ferrocyanide, $1 \mathrm{mM}$ magnesium chloride $0.002 \%$ NP- $40,0.01 \%$ sodium deoxycholate, PBS, pH 7.0 (ref. 58). Giemsa: Paraffin sections were rehydrated and stained for several hours at $37^{\circ} \mathrm{C}$ with standard Giemsa stain solution and subsequently rinsed in distilled water. The sections were differentiated with $0.5 \%$ aqueous acid acetic and rapidly dehydrated thereafter. For periodic acid Schiff staining: Paraffin sections were rehydrated, stained with periodic acid $0.5 \%$ for $10 \mathrm{~min}$, washed and stained again with Schiff reagent for $5 \mathrm{~min}$. After dehydration and xylene clearing, slides were mounted and visualized.

\section{Horseradish peroxidase staining and TUNEL analysis}

For horseradish peroxidase staining. Endogenous peroxidase activity was inhibited by incubating sections for $15 \mathrm{~min}$ in $1 \% \mathrm{H}_{2} \mathrm{O}_{2} /$ methanol. Sections were then boiled in $10 \mathrm{mM}$ citrate ( $\mathrm{pH}$ 6) for $15 \mathrm{~min}$ for antigen retrieval, rinsed in Tris- $\mathrm{HCl}, \mathrm{pH}$ 7.6, and blocked with normal goat serum (1:10) for $5 \mathrm{~min}$. Primary rat anti-mouse Ki67 (Dako M7249), rat anti-mouse F4/80 (Invitrogen MF48000) and S100 (Dako Z0311) antibodies were diluted 1:50, 1:20 and 1:1000, respectively, in Tris- $\mathrm{HCl}$, $\mathrm{pH} 7.6,0.5 \% \mathrm{BSA}$ and applied to sections for $1 \mathrm{~h}$ at room temperature. Following rinsing, specific binding was revealed by incubating with horseradish peroxidase (HRP)-conjugated goat anti-rat polyclonal antibody (1:200) for $30 \mathrm{~min}$ and subsequent incubation with a 50-fold diluted HRP substrate (DAB; DAKO) for $7 \mathrm{~min}$. Nuclei were counterstained using Harris haematoxylin. For TUNEL analysis: Following deparaffinization and rehydration, sections were pretreated with proteinase $\mathrm{K}\left(20 \mu \mathrm{g} \mathrm{ml}^{-1}\right.$ in PBS, $\left.30 \mathrm{~min}\right)$ at room temperature. PBS-rinsed sections were preincubated in TdT reaction buffer $(25 \mathrm{mM}$ Tris- $\mathrm{HCl}, 200 \mathrm{mM}$ sodium cacodylate, $0.25 \mathrm{mg} \mathrm{ml}^{-1} \mathrm{BSA}, 1 \mathrm{mM}$ cobalt chloride) for $10 \mathrm{~min}$ and incubated for $1-2 \mathrm{~h}$ at $37^{\circ} \mathrm{C}$ in a humidified chamber. The reaction was stopped by incubation with $300 \mathrm{mM} \mathrm{NaCl}$ and $30 \mathrm{mM}$ sodium citrate for $10 \mathrm{~min}$, and detection was performed with streptavidin-HRP in PBS for 20 min. Nuclei were counterstained with Gill's haematoxylin. Slides were dehydrated and covered with mounting medium. Positively stained cells were counted from three animals independently analysed per group. A minimum of three random pictures per section were taken using an Axion HRC (Carl Zeiss MicroImaging Inc.).

FACS analysis. Single cell suspensions were prepared from postnatal day- 6 ventral skin $^{31,32}$. After washing in PBS/5\% FCS, the cells were stained for flow cytometry using standard procedures. The following monoclonal antibody conjugates were used to define cell subsets: CD45-Alexa 700 (30.H12), CD11c-APC (N4/18), CD3-PE (17A2), F4/80-APC-efluoro 780 and TCRVg3-FITC (536). All were purchased from eBioscience, except TCR Vg3-FITC, which was purchased from BD Pharmingen. DAPI (Invitrogen) was used for dead cell discrimination. Samples were analysed on an LSR II Flow Cytometer (Becton Dickinson) equipped with 488, 407 and 640 lasers and data analysed with FlowJo software (TreeStar).

Electron microscopy. Skin biopsy samples were minced to $<0.5 \mathrm{~mm}^{3}$, fixed in modified Karnovsky's fixative overnight and postfixed in either $0.2 \%$ ruthenium tetroxide or $1 \%$ aqueous osmium tetroxide, containing $1.5 \%$ potassium ferrocyanide. After fixation, samples were dehydrated in a graded ethanol series, and embedded in an Epon-epoxy mixture. After selection of sites with perpendicular cross-sectioning in $1 \mathrm{~mm}$ toluidine blue-stained, epoxy-embedded sections, ultrathin sections were examined, with or without further contrasting with lead citrate, using a Zeiss 10A electron microscope (Carl Zeiss), operated at $60 \mathrm{kV}$.

Measurement of TEWL. The rate of TEWL from the ventral skin of preshaved, 2 -week-old, anaesthetized transgenic and littermate controls was measured using a Tewameter TM210 (Courage and Khazaka) ${ }^{8}$. The mean \pm s.e.m. is shown.

Western blot analysis. Skin was homogenized using Tissue Lyzer (Qiagen) in $8 \mathrm{M}$ urea, EDTA $10 \mathrm{mM}$, Tris- $\mathrm{HCl} 50 \mathrm{mM}$, pH 8. Following 30 min incubation on ice, lysates were centrifuged $\left(13,000 \mathrm{~g}\right.$ for $15 \mathrm{~min}$ at $\left.4{ }^{\circ} \mathrm{C}\right)$ and quantified using the Pierce BCA protein assay (Thermo Fisher Scientific). For SDS-PAGE, $50 \mu \mathrm{g}$ proteins was loaded and separated on a $4-16 \%$ acrylamide gradient gel. Western blot analysis was performed using rabbit anti-mouse antibodies to K14 $(1: 10,000)$ K1, K6, filaggrin, loricrin and involucrin (1:1,000, Covance). Signals were revealed using anti-rabbit immunoglobulin $\mathrm{G}$ from donkey $(1: 2,000)$ as secondary antibody and the Pierce Fast Western Blot Kit SuperSignal West Dura (Thermo Fisher Scientific) detection system.

Tight junction functional assay. Junctional integrity of the epidermis was addressed by assessing diffusion of intradermally injected NHS-LC biotin ${ }^{8}$. Staining was visualized using an LSM confocal microscope after incubation of sections with AlexaFluor 488-conjugated streptavidin (Invitrogen) overnight at $4^{\circ} \mathrm{C}$. Nuclei were counterstained with $0.2 \mathrm{\mu g} \mathrm{ml}^{-1}$ DAPI (Roche) in mounting media (Dako Schweiz AG).
Semiquantitative and quantitative RT-PCR. Skin was homogenized using Tissue Lyzer (Qiagen) and RNA was extracted with the Qiagen RNeasy Mini kit following the manufacturer's instructions. A volume of $1.5 \mu \mathrm{g}$ of RNA was treated with RQ1 RNase-free DNase and reverse transcribed using M-MLV Reverse Transcriptase RNase H Minus Point Mutant (Promega). Real-time PCR was performed by TaqMan PCR using Applied Biosystems 7500. Each measurement was taken in triplicate. Quantification of fluorescence was normalized to $\beta$-actin. Amplified PCR products were separated on $2 \%$ agarose gel and visualized by ethidium bromide staining. Primer sequences are shown in Supplementary Table S2.

Lipid analyses. Whole skin from newborns was removed at autopsy, frozen and stored at $-20^{\circ} \mathrm{C}$ until further treatment. Stratum corneum lipids were homogenized, lyophilized and weighted. Epidermal lipids were extracted for $24 \mathrm{~h}$ at $37^{\circ} \mathrm{C}$ in solvent mixtures (chloroform/methanol/water) ${ }^{59}$.

Statistical analysis. All data are expressed as means \pm s.e.m. Individual groups were compared using the Wilcoxon Mann-Whitney test, except for lipid analyses for which the Welch Two Sample Student's $t$-test was applied. A level of $P<0.05$ was considered statistically significant for all comparisons; ${ }^{*} P<0.05,{ }^{* *} P<0.01$ and ${ }^{* * *} P<0.001$

\section{References}

1. Meyer-Hoffert, U. Reddish, scaly, and itchy: how proteases and their inhibitors contribute to inflammatory skin diseases. Arch. Immunol. Ther. Exp. 57, 345-354 (2009).

2. Proksch, E., Brandner, J. M. \& Jensen, J. M. The skin: an indispensable barrier. Exp. Dermatol. 17, 1063-1072 (2008)

3. Huber, M. et al. Mutations of keratinocyte transglutaminase in lamellar ichthyosis. Science 267, 525-528 (1995).

4. Basel-Vanagaite, L. et al. Autosomal recessive ichthyosis with hypotrichosis caused by a mutation in ST14, encoding type II transmembrane serine protease matriptase. Am. J. Hum. Genet. 80, 467-477 (2007).

5. Descargues, P. et al. Spink5-deficient mice mimic Netherton syndrome through degradation of desmoglein 1 by epidermal protease hyperactivity. Nat. Genet. 37, 56-65 (2005)

6. Netzel-Arnett, S. et al. Membrane anchored serine proteases: a rapidly expanding group of cell surface proteolytic enzymes with potential roles in cancer. Cancer Metastasis Rev. 22, 237-258 (2003)

7. List, K. et al. Matriptase/MT-SP1 is required for postnatal survival, epidermal barrier function, hair follicle development, and thymic homeostasis. Oncogene 21, 3765-3779 (2002).

8. Leyvraz, C. et al. The epidermal barrier function is dependent on the serine protease CAP1/Prss8. J. Cell Biol. 170, 487-496 (2005).

9. Szabo, R., Kosa, P., List, K. \& Bugge, T. H. Loss of matriptase suppression underlies spint1 mutation-associated ichthyosis and postnatal lethality. Am. J. Pathol. 174, 2015-2022 (2009).

10. List, K. et al. Deregulated matriptase causes ras-independent multistage carcinogenesis and promotes ras-mediated malignant transformation. Genes Dev. 19, 1934-1950 (2005).

11. Rawlings, N. D., Morton, F. R., Kok, C. Y., Kongand, J. \& Barrett, A. J. MEROPS: the peptidase database. Nucleic Acids Res. 36, 320-325 (2008).

12. Yu, J. X., Chao, L. \& Chao, J. Prostasin is a novel human serine proteinase from seminal fluid. Purification, tissue distribution, and localization in prostate gland. J. Biol. Chem. 269, 18843-18848 (1994).

13. Vuagniaux, G. et al. Activation of the amiloride-sensitive epithelial sodium channel by the serine protease mCAP1 expressed in a mouse cortical collecting duct cell line. J. Am. Soc. Nephrol. 11, 828-834 (2000).

14. Heutinck, K. M., ten Berge, I. J., Hack, C. E., Hamann, J. \& Rowshani, A. T. Serine proteases of the human immune system in health and disease. Mol. Immunol. 47, 1943-1955.

15. Dery, O., Corvera, C. U., Steinhoff, M. \& Bunnett, N. W. Proteinase-activated receptors: novel mechanisms of signaling by serine proteases. Am. J. Physiol. 274, C1429-1452 (1998).

16. Camerer, E. et al. Local protease signaling contributes to neural tube closure in the mouse embryo. Dev. Cell 18, 25-38 (2010).

17. Steinhoff, M. et al. Proteinase-activated receptor- 2 in human skin: tissue distribution and activation of keratinocytes by mast cell tryptase. Exp. Dermatol. 8, 282-294 (1999).

18. Steinhoff, M. et al. Agonists of proteinase-activated receptor 2 induce inflammation by a neurogenic mechanism. Nat. Med. 6, 151-158 (2000).

19. Shpacovitch, V. M. et al. Agonists of proteinase-activated receptor 2 induce cytokine release and activation of nuclear transcription factor kappaB in human dermal microvascular endothelial cells. J. Invest. Dermatol. 118, 380-385 (2002)

20. Steinhoff, M. et al. Proteinase-activated receptor- 2 mediates itch: a novel pathway for pruritus in human skin. J. Neurosci. 23, 6176-6180 (2003).

21. Derian, C. K., Eckardt, A. J. \& Andrade-Gordon, P. Differential regulation of human keratinocyte growth and differentiation by a novel family of proteaseactivated receptors. Cell Growth Differ 8, 743-749 (1997). 
22. Hachem, J.- P. et al. Serine protease signaling of epidermal permeability barrier homeostasis. J. Invest. Dermatol. 126, 2074-2086 (2006).

23. Shimada, S. G., Shimada, K. A. \& Collins, J. G. Scratching behavior in mice induced by the proteinase-activated receptor-2 agonist, SLIGRL-NH2. Eur. J. Pharmacol. 530, 281-283 (2006).

24. D’Andrea, M. R. et al. Characterization of protease-activated receptor- 2 immunoreactivity in normal human tissues. J. Histochem. Cytochem. 46, 157-164 (1998).

25. Munz, B. et al. Overexpression of activin A in the skin of transgenic mice reveals new activities of activin in epidermal morphogenesis, dermal fibrosis and wound repair. EMBO J. 18, 5205-5215 (1999)

26. Zettersten, E. et al. Recessive $\mathrm{x}$-linked ichthyosis: role of cholesterol-sulfate accumulation in the barrier abnormality. J. Invest. Dermatol. 111, 784-790 (1998).

27. Doering, T. et al. Sphingolipid activator proteins are required for epidermal permeability barrier formation. J. Biol. Chem. 274, 11038-11045 (1999).

28. Feingold, K. R. Thematic review series: skin lipids. The role of epidermal lipids in cutaneous permeability barrier homeostasis. J. Lipid Res. 48, 2531-2546 (2007)

29. Li, M. et al. RXR-alpha ablation in skin keratinocytes results in alopecia and epidermal alterations. Development 128, 675-688 (2001).

30. Hussein, M. R. Skin-limited Langerhans' cell histiocytosis in children. Cancer Invest. 27, 504-511 (2009).

31. Dumortier, A. et al. Atopic dermatitis-like disease and associated lethal myeloproliferative disorder arise from loss of notch signaling in the murine skin. PloS One 5, e9258 (2010)

32. Ferrero, I., Wilson, A., Beermann, F., Held, W. \& MacDonald, H. R. T cell receptor specificity is critical for the development of epidermal gammadelta T cells. J. Exp. Med. 194, 1473-1483 (2001).

33. Soumelis, V. et al. Human epithelial cells trigger dendritic cell mediated allergic inflammation by producing TSLP. Nat. Immunol. 3, 673-680 (2002).

34. Ting, S. B. et al. Inositol- and folate-resistant neural tube defects in mice lacking the epithelial-specific factor Grhl-3. Nat. Med. 9, 1513-1519 (2003).

35. Ting, S. B. et al. A homolog of Drosophila grainy head is essential for epidermal integrity in mice. Science 308, 411-413 (2005).

36. Lindner, J. R. et al. Delayed onset of inflammation in protease-activated receptor-2-deficient mice. J. Immunol. 165, 6504-6510 (2000).

37. Briot, A. et al. Kallikrein 5 induces atopic dermatitis-like lesions through PAR2-mediated thymic stromal lymphopoietin expression in Netherton syndrome. J. Exp. Med. 206, 1135-1147 (2009).

38. Chavanas, S. et al. Mutations in SPINK5, encoding a serine protease inhibitor, cause Netherton syndrome. Nat. Genet. 25, 141-142 (2000)

39. Alvarez, D., Vollmann, E. H. \& von Andrian, U. H. Mechanisms and consequences of dendritic cell migration. Immunity 29, 325-342 (2008).

40. Ramelli, G. et al. Protease-activated receptor 2 signalling promotes dendritic cell antigen transport and T-cell activation in vivo. Immunology 129, 20-27 (2010).

41. Steinhoff, M. et al. Neurophysiological, neuroimmunological, and neuroendocrine basis of pruritus. J. Invest. Dermatol. 126, 1705-1718 (2006)

42. Vergnolle, N., Ferazzini, M., D’Andrea, M. R., Buddenkotte, J. \& Steinhoff, M. Proteinase-activated receptors: novel signals for peripheral nerves. Trends Neurosci. 26, 496-500 (2003)

43. List, K. et al. Loss of proteolytically processed filaggrin caused by epidermal deletion of Matriptase/MT-SP1. J. Cell Biol. 163, 901-910 (2003).

44. Nagaike, K. et al. Defect of hepatocyte growth factor activator inhibitor type 1 /serine protease inhibitor, Kunitz type 1 (Hai-1/Spint1) leads to ichthyosislike condition and abnormal hair development in mice. Am. J. Pathol. 173, 1464-1475 (2008)

45. Briot, A. et al. Par2 inactivation inhibits early production of TSLP, but not cutaneous inflammation, in Netherton syndrome adult mouse model. J. Invest. Dermatol. 130, 2736-2742 (2010).

46. Sales, K. U. et al. Matriptase initiates activation of epidermal pro-kallikrein and disease onset in a mouse model of Netherton syndrome. Nat. Genet. 42, 676-683 (2010).

47. Andreasen, D., Vuagniaux, G., Fowler-Jaeger, N., Hummler, E. \& Rossier, B. C. Activation of epithelial sodium channels by mouse channel activating proteases (mCAP) expressed in Xenopus oocytes requires catalytic activity of mCAP3 and mCAP2 but not mCAP1. J. Am. Soc. Nephrol. 17, 968-976 (2006).

48. Chen, M., Fu, Y. Y., Lin, C. Y., Chen, L. M. \& Chai, K. X. Prostasin induces protease-dependent and independent molecular changes in the human prostate carcinoma cell line PC-3. Biochim. Biophys. Acta 1773, 1133-1140 (2007).
49. Rossier, B. C. \& Stutts, M. J. Activation of the epithelial sodium channel (ENaC) by serine proteases. Annu. Rev. Physiol. 71, 361-379 (2009).

50. Hummler, E. et al. Early death due to defective neonatal lung liquid clearance in alpha-ENaC-deficient mice. Nat. Genet. 12, 325-328 (1996).

51. Charles, R. P. et al. Postnatal requirement of the epithelial sodium channel for maintenance of epidermal barrier function. J. Biol. Chem. 283, 2622-2630 (2008).

52. Buddenkotte, J. et al. Agonists of proteinase-activated receptor-2 stimulate upregulation of intercellular cell adhesion molecule-1 in primary human keratinocytes via activation of NF-kappa B. J. Invest. Dermatol. 124, 38-45 (2005).

53. Spacek, D. V. et al. The mouse frizzy (fr) and rat 'hairless' (fr(CR)) mutations are natural variants of protease serine $\mathrm{S} 1$ family member 8 (Prss8). Exp. Dermatol. 19, 527-532 (2010).

54. Wankell, M. et al. Impaired wound healing in transgenic mice overexpressing the activin antagonist follistatin in the epidermis. EMBO J. 20, 5361-5372 (2001).

55. Porret, A., Merillat, A. M., Guichard, S., Beermann, F. \& Hummler, E. Tissuespecific transgenic and knockout mice. Methods Mol. Biol. 337, 185-205 (2006).

56. Pirrone, A., Hagerand, B. \& Fleckman, P. Primary mouse keratinocyte culture. Methods Mol. Biol. 289, 3-14 (2005).

57. Planes, C. et al. In vitro and in vivo regulation of transepithelial lung alveolar sodium transport by serine proteases. Am. J. Physiol. Lung Cell Mol. Physiol. 288, 1099-1109 (2005).

58. Schlaeger, T. M., Qin, Y., Fujiwara, Y., Magramand, J. \& Sato, T. N. Vascular endothelial cell lineage-specific promoter in transgenic mice. Development 121, 1089-1098 (1995).

59. Reichelt, J., Breiden, B., Sandhoff, K. \& Magin, T. M. Loss of keratin 10 is accompanied by increased sebocyte proliferation and differentiation. Eur. J. Cell Biol. 83, 747-759 (2004).

\section{Acknowledgments}

We thank Sabine Werner (ETH Zürich) for kindly providing the Keratin-14 promoter construct; Andrée Porret, Anne-Marie Mérillat, Sabrina Guichard and Heike Hupfer for excellent technical assistance; the members of the Hummler lab for discussions; and Bernard Rossier for critical reading of the manuscript. We are grateful to the Mouse Pathology platform and the Cellular Imaging Facility platform, University of Lausanne. We thank Giancarlo Ramelli for help with PAR2 $2^{-1}$ genotyping and Jean-Philippe Antonietti for help with the statistical analyses. This work was supported by the Swiss National Science Foundation (Grant 3100A0-102125/1 to E. Hummler), by the German Research Foundation (DFG, SFB 645), by the seventh framework programme of the EU-funded 'LipidomicNet' (proposal number 202272) to K. Sandhoff and by the National Institutes of Health (S. Coughlin) and Inserm Avenir (E. Camerer)

\section{Author contributions}

S.F. conducted most of the experiments. E.C. and S.R.C. designed and performed $\mathrm{Grhl}^{\text {PAR2/+ }}$ generation and characterization. G.C., S.R., M.M., R.-P.C., F.B., J.-C.S., B.B. K.S., S.R., A.W., M.H., S.R. and M.S. conducted and assisted in experiments. S.F., E.C. and E.H. wrote the manuscript. E.H. designed and supervised the study.

\section{Additional information}

Supplementary Information accompanies this paper at http://www.nature.com/ naturecommunications

Competing financial interests: The authors declare no competing financial interests.

Reprints and permission information is available online at http://npg.nature.com/ reprintsandpermissions/

How to cite this article: Frateschi, S. et al. PAR2 absence completely rescues inflammation and ichthyosis caused by altered CAP1/Prss 8 expression in mouse skin. Nat. Commun. 2:161 doi: 10.1038/ncomms1162 (2011).

License: This work is licensed under a Creative Commons Attribution-NonCommercialNoDerivative Works 3.0 Unported License. To view a copy of this license, visit http:// creativecommons.org/licenses/by-nc-nd/3.0/ 